\title{
Worth and Human Values at the Centre of Designing Situated Digital Public Displays
}

\author{
Nuno Otero \\ Department of Information Systems, University of Minho, Portugal \\ Rui José \\ Department of Information Systems, University of Minho, Portugal
}

\begin{abstract}
The development and design of computational artefacts and their current widespread use in diverse contexts needs to take into account end-users needs, likes/dislikes and broader societal issues including human values. However, the fast pace of technological developments highlight that the process of defining the computational artefacts not only needs to understand the user but also engineers and designers' creativity. Considering these issues, we have been exploring the adoption of the WorthCentred Design framework, proposed by Gilbert Cockton, to guide our development efforts regarding situated digital public displays.

We will present our insights as a design team regarding the use of the WCD framework for the on-going development of situated digital public displays. Furthermore, we will discuss our current efforts to extend the adoption of the framework. Finally, future steps are presented, and will focus on enriching our understanding concerning potential places for situated digital displays, stakeholders' views, encouraging open participation and co-creation.
\end{abstract}

Keywords: Situated Public Digital Displays; Human Values; Worth-Centered Design; Interaction Design; Co-creation

\section{INTRODUCTION}

The creation of novel digital artifacts, including pervasive and ubiquitous computational artifacts, for diverse contexts of utilization and fruition is a process that should go far beyond the definition of its form and functionality. For example, it should take into account the way that the artifact is going to fit into the larger context of daily life and into the eco-system of already existing services and artifacts. In fact, in addition to the technological challenges that are involved, designing digital artifacts requires a thorough understanding of the social milieu that the system is meant to integrate, a clear view of the respective value proposition and the engendered users' experiences (Sellen, Rogers, Harper, \& Rodden, 2009).

Reflections on human values and the development of digital artefacts is not a new theme. Computers and other digital technologies have been raising important concerns regarding ethical principles (see, for example, Johnson, 2004). The mediation of human actions by these new types of technologies pose distinct challenges and the field of computer ethics is active in 
defining ethical boundaries and trying to inform policy vacuums (Johnson, 2004): “Computer technology instruments human action in ways that turn very simple movements into very powerful actions" (pag. 76). As a simple example, consider the case of cyber-bullying in schools and its consequences in terms of publicizing, social identities and images of the self.

Sellen et al (2009) consider that: “...values are not something that can be catalogued like books in a library but are bound to each other in complex weaves that when tugged in one place, pull values elsewhere out of place." (pag. 61). Furthermore, understanding human values means not only taking the perspective of the individual but also looking at other levels of social organization, like groups, Institutions or even societies. Different human values might be particularly cherished by distinct agents at specific points in time and space. The design of interactions and technologies, in this sense, needs to be aware of the different balances and make choices (Sellen et al., 2009). Although they propose a new stage of the design cycle especially concerned with the referred to issues, it seems that the field is still quite open regarding how to proceed in terms of methodologies and methods.

In their seminal work, Friedman et al. (Friedman, 1996; Friedman, Kahn Jr, \& Borning, 2006; Friedman \& Kahn Jr, 2003) have proposed a framework which they termed Value Sensitive Design that considers three distinct aspects/investigations that should inform design:

- Conceptual investigations intend to understand which values are at stake within a certain project from a philosophical stance. It involves reflecting on stakeholders views, assumptions about networks of values and possible trade-offs.

- Empirical investigations focus on how the conceptual issues uncovered are actually instantiated in real contexts. Researchers should formulate particular empirical questions regarding usage and perceived valuation by stakeholders in order to reach understanding based on real world data.
- Technical investigations try to uncover how specific systems' functionalities are tied to particular values and assess support or hindrance.

According to Friedman et al. (2006), the framework "...can help researchers uncover the multiplicity of and potential conflicts among human values implicated in technological implementations." (pag. 356). They identify eight features of their framework that can be seen as guiding principles for design. In a nutshell, these eight features cover: the importance of considering values early in the design process, highlight the need to be open to a wide set of potential values, consider the need to distinguish usability issues from value issues, takes an interactional perspective regarding the relations between features of the technologies and their use by people, and considers the psychological proposition that certain values are universally held.

Their Value Sensitive Design framework also offers practical advice on how to proceed with such investigations but it seems that there is a lack of supporting tools to "organize" the vast amount of knowledge and issues that such enterprise can raise. Furthermore, an over reliance on preassumed lists of values not only might create problems regarding their meaning and classification but can also hinder openness to the richness of context and discussion with real users about their take on the values and worth of the systems and/or specific functionalities (see, for example, Dantec, Poole, \& Wyche, 2009).

This present paper will describe and discuss a case study where a particular framework was adopted to foster the inclusion of human values and worth in the design cycle.

The remaining of the paper will go as follows. First, some background regarding the design and development of situated digital public display will be covered as well as a particular framework being developed by Gilbert Cockton termed Worth-Centred Design (WCD) (Cockton, 2004, 2005 , 2006). The paper proceeds with the presentation of a case study where the WCD was 
utilized to frame the design process. The discussion section presents some reflections regarding the adoption of the WCD framework, considering its possible benefits and challenges. In the conclusions, we consider some concluding lessons learned and next steps, in particular our goal of setting up a Living Lab for the development and design of situated public digital displays

\section{BACKGROUND}

\section{The design and development of situated digital public displays}

In recent years public digital displays have become increasingly common in all sorts of places, from train stations to shopping centers or bars. We view public digital displays as an important enabling technology for many types of ubiquitous computing scenarios. They can provide a simple and effective way for bringing digital information into our physical world. Furthermore, interactive displays promise much potential for leading people to interaction and that can be crucial for the generation of pervasive usergenerated content back to the virtual world.

However, in many cases, digital public displays essentially serve pre-determined content in a push-based model, offering very little in ways of interacting with and responding to the people around them. The growing perception that there should be more effective ways to take advantage of their strong communication potential, together with the emergence of new sensing technologies, are leading to new concepts of public display that are more tightly integrated within their surroundings and able to play a vital role in the way people understand, navigate and behave in their environment (O'Hara, Perry, Churchill, \& Russell, 2003).

Our on-going long term research goal concerns the investigation of the design space of interactive and digital public displays as an enabling artifact to support people's situated interactions in public spaces (José, Otero, Izadi, \& Harper, 2008). In fact, with the Instant Places technology currently being developed at the University of Minho, digital displays can have multiple sensing capabilities and are able to adapt their behaviour according to the history of interactions they have sensed. This also gives them the ability to adapt to the particular place where they are located, thus making them situated displays.

Nevertheless, research has highlighted that enticing people to participate is a major challenge (Brignull, Izadi, Fitzpatrick, Rogers, \& Rodden, 2004; Huang, Mynatt, Russel, \& Sue, 2006), and there are complex issues related with publication management.

\section{The Worth-Centred Design Framework}

On top of our current concern regarding the inclusion of human values in the design cycle, the broad range of elements that may affect the design process of pervasive and ubiquitous computational artifacts and the large number of individual characteristics that can be considered, necessarily forces the designer to make a judgment on which data to include in the process and how to value it (Löwgren \& Stolterman, 2007). Furthermore, any context of utilization and development represents a challenge of its own bringing all sorts of implications to the design process. The design process will have to ground itself on a careful definition of the ultimate purpose of the system and an understanding of the specific social setting for which it is being created. Nevertheless, thoughtful analysis concerning the design process and the outcomes of it will suggest similarities, for example systems that share similar purposes and are designed for similar social settings. An understanding of these similarities can provide parts of the design map that inspire each new design process. Basically, design teams need to "learn" how past experiences regarding the design process and outcomes can be re-used.

In order to tackle some of the challenges just considered and the inclusion of human values in the design cycle, we have been exploring the adoption of the Worth-Centred Design framework (WCD), proposed by Gilbert Cockton, to guide 
our development efforts regarding situated digital public displays (Cockton, 2004, 2005, 2006, 2008, 2009). The WCD can be seen as a conceptual framework that intends to facilitate the process of making explicit the connections between high level concepts related to desired ends/worth/values and simple/basic/atomic features composing an (or to be) artifact. The framework is worth-centred because it considers the net benefits that arise from the interaction of positive values and more negative aversions: the benefits of ownership and usage should thus be worth their costs.

The WCD framework intends to facilitate the process of making explicit the connections between high-level concepts and features composing an artifact (Cockton, 2004, 2005, 2008, 2009). By making the design team reflect on the connections of worth/values and design elements the different paths/threads from wished issues to actual products can be highlighted avoiding pitfalls of product reification (centering the attention on the product features and not on the supporting human activities) and false starts on usability issues to be tackled. Furthermore, the framework can also be seen as a way to provide common ground between results obtained from marketing research and the actual translations of the findings into product requirements and specifications.

The WCD framework does not strictly postulate a specific methodology or set of methods. However, it does propose a set of design principles and tools to encapsulate the perceived connections and foster reflection on the design (Cockton 2008):

- Commitment, concerns the need to champion human value.

- Receptiveness, involves picking up the initial ideas regarding the uncovering of sensitivities and try to flesh them out through research and usage studies.

- Expressiveness, considers the need for the externalization of the connections between values and product features (including inbetween layers that the author identifies, see below).
- Inclusiveness, argues that the views of all stakeholders should be taken into account.

- Credibility, involves reflecting on the feasibility implied by the connections established. Improvability, considers the need to provide metrics that show progress towards accounting of the alternative designs under scrutiny.

\section{WCD approaches}

WCD approaches are a set of techniques tailored specifically for the process of WCD (Cockton, 2004, 2005, 2008). They support the key principles of the WCD design and provide a practical framework around which the different design activities can be organized.

Worth maps are a network type diagrams, adapted from the hierarchical value models (HVMs) used in the consumer psychology area. The worth maps try to make explicit the different means-end chains (MECs) that a certain initial idea and/or artefact might suggest and are the centre piece of the framework structuring the design processes. The worth maps are composed of:

- Design elements:

o Materials: are system subcomponents sourced from elsewhere, with at most some parametrizing or forming. Material selection is inspired by previous designs, current needs/opportunities and technological trends.

oFeatures: are system components composed from materials. Features have to be parts, (or non-exhaustive groups of parts).

○Qualities: are primarily people's immediate feelings about things. Qualities and defects are expressed as abstractions. Some may be revealed to a designer's judgement or 'good taste', but some are empirically measurable. They are sensed at the onset of experience.

- Value elements: 
oUser experiences: include issues usage, perceived and thought value regarding the artifact by the people experiencing it. It implies considering first encounters and long term appropriation.

oOutcomes: are enduring changes within people or in the world that outlive an interaction. These are reportable, observable, or both. Worthwhile outcomes are the happy endings in a worth delivery scenarios (Cockton 2009).

Two other important concepts of the WCD framework are Element Measurement Strategies (EMSs) and Direct Worth Instrumentation (DWIs).

The EMSs intend to clearly address the issue of having concrete measures for evaluating the elements present in a worth map. Thus, it associates instruments and measures with distinct element of the worth map. Another central idea of this concept is that evaluation cannot be restricted to immediate usage issues. The evaluation must go beyond traditional usability testing and include assessment of the worthwhile outcomes. This inclusion implies the need to track the wider context and see/measure the consequences of the system/artefact utilization on the far side of immediate interaction (in a broad sense, which means it also covers the enduring memory/experience traces people create).

The DWIs are a reflection of the EMS and demands the creation of appropriate operationalizations of the things to be measured/captured, even if this involves the creation of instruments "outside" the developed application/system (taking the broader view as referred to above).

\section{Stages and methods}

As already referred to above, the WCD framework does not postulate a strict set of stages or specific methods to inform the creation of worth maps.

However, Cockton suggests the following in relation to the actual construction of worth map diagram: (a) the design team should start with fairly open brainstorming session in order to inquire about the team's assumptions regarding technical and human sensitivities, (b) the next step involves translating the elicited sensitivities into concrete design elements, taking note of their origin and displaying them appropriately in layers to serve the actual construction of the diagram; (c) in the last step the diagram's elements should now be in place and the design team will need to reflect and make explicit the different connections and chains.

In relation to the methods to generate the relevant information for the construction of the diagram, brainstorming sessions and workshops with the inclusion of potential end users seem to be a worthwhile investment. Another strong possibility is the use of scenarios, where stories are created about the users and their interactions with artifacts in a specific context (Carroll, 1995, 2000; Preece, Rogers, \& Sharp, 2002). Scenarios allow the exploration and discussion of contexts, needs and corresponding requirements. Conducting group and individual interviews to potential end-users is also a valuable tool to inquire and elicit ideas about worth and value.

Summarizing, for the moment one cannot postulate a concrete recipe for success. As a rule of thumb researchers and practitioners need to be aware of the design situation, the particulars of the envisioned product/service, the end-users and stakeholders and make an informed decision regarding the most appropriate methods to collect information for the worth map and respecting the design principles considered.

\section{THE CASE STUDY}

In the case study presented here it was the design team that approached the stakeholders with the proposal to create a new artifact to enhance their activity and not the other way around. In other words, although the design team was confident that something worthwhile could be produced people involved in these particular contexts did not seem to be actively engaged in looking for a solution to specific a problem.

Such framing poses challenges concerning the initial definition of what can be requirements and 
methods to elicit them. We should also point out that this present work is still in progress since the overall project continues and we expect to progress beyond the issues referred to in this paper. More specifically, all the data collected and the analysis done will enable us to more confidently approach the creation and implementation of the EMS and the DWI. Furthermore, we will produce new prototypes to be deployed and evaluated.

\section{The setting and other contextual factors}

This case study involves the on-going development of a digital public display for a teachers' common room in a secondary school. The teacher's common serves around 120 people, which can be considered our primary users. The room not only provides a space for socializing but is also an access point to collect the classes' administrative forms and be informed about the school procedures. These characteristics make this common room a very busy passing space.

Two distinct displays show information about the school: formal notifications from the school administration, information about unions and training projects. There is also a particular corner of the room where cultural initiatives and informal notes are displayed on a table. The potential "users" of the digital display under development comprises the actual teachers and other stakeholders that regularly send information to the displays (for example, board of Directors, official information from the Ministry of Education, other educational organizations with connection to the school, the unions etc). Specific people are in charge of authorizing the posting of information in the official displays. Furthermore, the person who actually posts the information needs to manage the available space and update the display accordingly.

It seems that a well defined structure is in place and known social rules govern the display of information in this common room. The design of the digital display will need to be aware of these issues and consider the overall impact of the artifact (who contributes, who is willing to contribute, how authorisations are carried out, who will benefit and who sees an increase of his/her work).

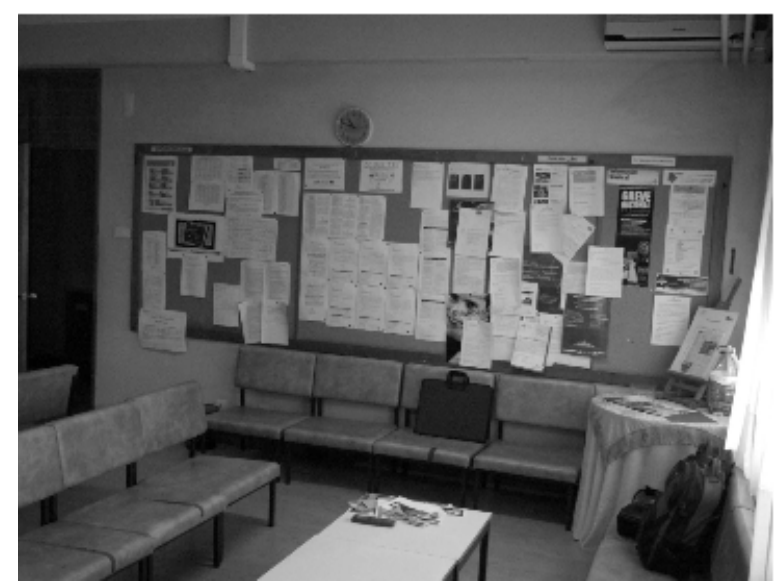

Figure 1 - Photograph of the teacher's common room and the available display

\section{The interaction design process followed and the insights collected}

The design team was composed of two researchers and one Master's student. The Master's student is a teacher at the school where the study was taking place.

The first step: meetings of the design team.

Firstly we conducted a series of meetings of the design team to discuss general features of the digital display and to reflect about our assumptions concerning use. It should be noted that our research group is actively developing expertise in the field of situated digital displays and, obviously, our experience of other projects we conducted was influential - we were not starting from scratch regarding the design of digital displays. Thus, based on our previous knowledge and the understanding of the specific context coming from the experience of the Master's student, we decided we to conduct semistructured interviews with teachers. The aim of these interviews was to complement our understanding regarding the use of the place. The 
interviews were centred around the following questions:

-What is the first thing people do when entering the common room?

-Which places draw their attention within the room?

-What kind of things did people suggest in order to make the place more pleasant?

-What do they use the place?

\section{Second step: interviewing teachers.}

In the second step, five initial individual interviews with teachers were conducted. The interviews were run by one of the researchers and the Master's student. Notes of the interviews were taken on spot and reviewed. The analysis of the interviews was fairly qualitative and allowed the emergence of the following main themes:

-Looking for official school information on the main display is a top priority when entering the room.

-Attention to the other display and informal corner of news and activities needs saliency.

-People seem to regard the place as too formal and wish it could be less so.

-The teachers use the place to work, be updated of news and socialize.

\section{Step three: designing the first worth map and defining the first prototype.}

Based on the analysis of the interviews the design team discussed the findings and draw the first worth map (see Figure 2).

Four main issues shaped our framing of the problem space:

-Teachers would like to be reassured that they were not missing important information - being informed of relevant news is important.

-The common room as viewed as too formal the common room needs to be less formal and probably new artifacts should foster this aspect.

-Considering the nature of the digital display and its flexibility on showing content, implementing distinct time cycles for the different types of information could improve people's feeling of keeping informed and, at the same time, provide content for informal conversations.

-The update of information would need to reflect its formal and informal nature - the design of the digital display needs to be aware of the organizational specificities.

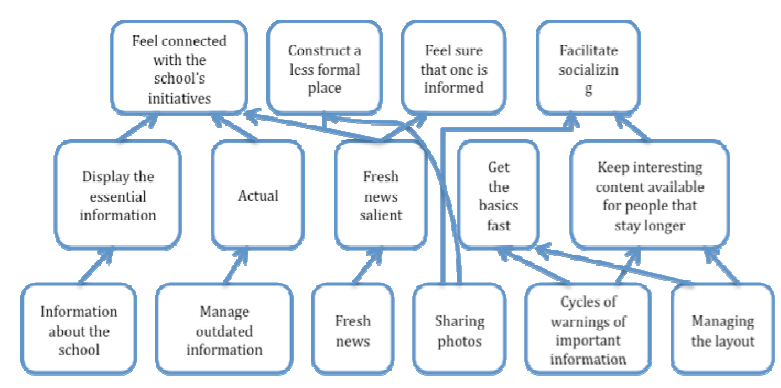

Figure 2 - Initial worth map for the teachers' common room digital display. First row of boxes corresponds to features, the second row to qualities and the top row to higher level themes like values or worth.

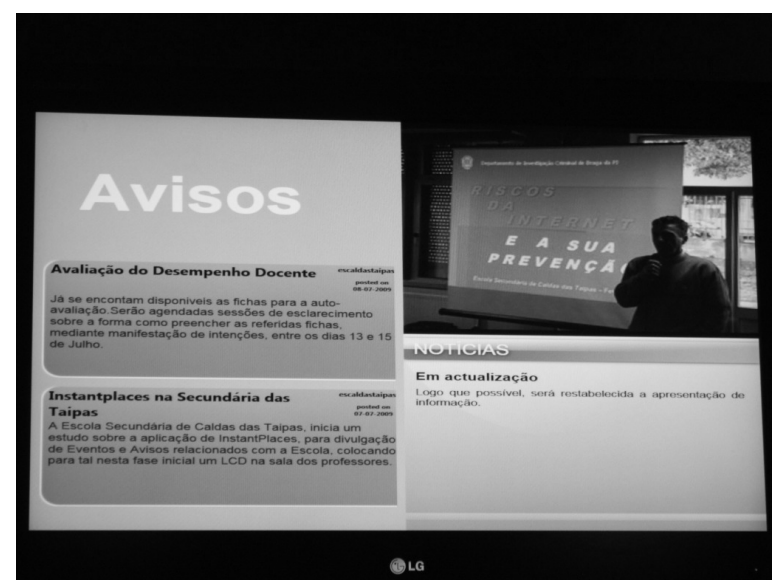

Figure 3 - Photograph of the digital display deployed at the teachers' common room

As can be seen in Figure 3, the layout of the display is organized taking into consideration three areas:

a) one main area where official information is provided - left side;

b) on the top right side there is an area where photos( using Flickr) and written contributions from teachers can be visualized (using blogs and twitter etc); 
c) on the bottom right side general news are displayed.

\section{Step 4 - deploying the prototype and conducting follow-up interviews.}

In step four a prototype was deployed at the teacher's common room for ten days. A preliminary analysis of the system's logs concerning the teachers' contributions to the display suggest that people were not too keen on actively writing content. In same cases, the Master's student, teacher of the school, was the main provider of content and was approached by colleagues to write some news and updates. Furthermore, anecdotal evidence points to the fact that some of his colleagues also seemed unaware of the possibilities open by the utilization of Flickr and Twitter and thus did not take advantage of such.

Three individual interviews were once again conducted by the same elements of the design team. This time, however, the focus of the questions was on people's first impressions of the digital display and ways to improve it.

All the three interviewees noticed the display when it was deployed at the common room. They also agreed that it seemed to be a good idea and could facilitate their search for new information. Clearly, the digital display was seen as a complement to the traditional forms of information dissemination already in place and not as a replacement. They also enjoyed the mix between formal and informal information, but were not clear regarding their role in updating the informal news channel. It seems they were aware of the social context and of the different "groups" present. Initiatives seem to be more group bound instead of individuals. One of the interviewees noted that some of the school's infra-structure could be adapted to feed the formal information channel and regarded this aspect important and beneficial. One other pointed out that more time was needed for appropriation and that these type of display could be used to foster communication between students and teachers. Finally, one of the interviewees made a specific design contribution.
He basically draw our attention to the fact that the current design was not giving any indication of the actual number of important news circulating. In other words, if there were too many news to be displayed at a particular moment the person was kept unaware of the ones not being currently displayed making it annoying to wait to see the whole cycle or missing something relevant.

\section{DISCUSSION}

In relation to the utilization of the WCD to frame our efforts, the design process followed in the case study presented and the particular externalization of ideas, assumptions and design alternatives helped reflection. The exercise of explicitly stating the connections between features, qualities and higher-level constructs about use fostered critical thinking and search for alternative design solutions. In the WCD framework, the clear decoupling of means and ends facilitates the understanding of how particular features might aid or hinder distinct values. These distinct (or even contradicting) values might come from different stakeholders' perspectives and the clear identification of the connections might help define trade-offs and inform design decisions. Curiously, we believe that the design process also made adherence to the design principles referred to easier. In fact, it seems to us that a virtuous cycle is in place: somehow the design principles seem to be encapsulated in the design cycle envisioned while adherence to the design principles makes the design process and corresponding methods meaningful.

We are aware that EMS and DWI were not fully fledged and implemented up to the moment. However, the knowledge gathered up to now is extremely valuable in order to proceed confidently with its construction and implementation. The following topics seem relevant:

- Are teachers better informed with the public display in place? Do they feel better informed? How do other stakeholders consider the worth of the system? 
- Is the system able to foster a more informal setting? Does the display of blogs, photos and twitter postings contributes to this?

- Does the system reflect the needs and organizational constraints of the school? Can formal information be easily fed to the systems without creating work overload to someone within the organizational chain?

- To what extent can the system improve the awareness of the on-going projects and work between teachers and students? Can this same concept be considered for an enlarged community and include other schools and Institutions in a network of public displays?

Agreeing with the terms of the WCD framework is not easy in the beginning of the process and people should expect some initial struggles regarding meaning and scope. However, after the first steps we think common ground emerges. Furthermore, although it seems plausible to assume that with the on-going development of the WCD framework terms can get clearer (maybe with more examples or extended explanations of case studies), we also believe that the definition of the terms is an exercise the design team needs to go through in order to commit themselves to this particular design stance (in particular, truly take on board an understanding of human values into the design cycle) (see, Cockton, Kujala, Nurkka, \& Hölttä, 2009, for a similar line of argumentation).

Nevertheless, more research is needed in order to understand what is the best way to elicit worth and values from end users. We are actively exploring different types of interviewing techniques. Furthermore, considering the scope of the WCD and the different tools it proposes (like diagrammatic representations, tables, textual descriptions etc), there is a need to create mechanisms to manage the connections between the different external representations built along the design process. Moreover, more research can be conducted to elucidate how the design teams (or even how different design teams) take advantage of the distinct external representations being proposed.

\section{CONCLUSIONS AND FUTURE STEPS}

In this paper we discussed a case study where the WCD framework was utilized to drive the design and development processes, and identified some pros and cons of the actual state of affairs. Following Sellen et al. (2009), an important current challenge is to create some kind of "lingua franca" that facilitates focus, transfer of knowledge and understanding.

In relation to our current project, we also believe that there are good reasons to go one step further regarding the creation of supporting mechanisms for the design and development of situated digital public displays. Our experience also tells us that one of the key problems concerning the design and development of this type of technology resides in the need to observe how they are used in the type of environment for which they are being designed. Such exercise requires an eco-system of services, communities and places that is not easy to create on a lab or small-scale demonstrator. Simulations and lab experiments may be useful for early evaluations, but they sacrifice the richness, unpredictability and diversity of the social environment of a real setting. Thus, the effective development of these technologies must be strongly anchored on longterm deployments in real settings. However, the authors are well aware of the challenges involved in public display deployments. Like any other real world experiment, public display deployments can face all sorts of unexpected and strongly limiting problems as reported in (Storz et al., 2006). In addition to the high costs involved, such deployments can be very time consuming, and there is a real risk that the major effort gets diverted from the initial innovation objectives into the mundane issues arising from the practicalities of putting the system to work.

One possible solution is to combine costeffective deployments with a flexible framework for experimentation and exploration of new 
concepts. In order to realize such solution a Living Lab is being set up to serve as a research tool shared between multiple projects and also with researchers from other institutions - Living Lab within Living LabMinho. The Living Lab on Situated Displays aims to create a long-term open environment for experimentation and co-creation in situated displays (see, Følstad, Brandtzæg, Gulliksen, Näkki, \& Börjeson, 2009, for a discussion regarding the term Living Lab). It will gather and orchestrate a relevant community of users and stakeholders in a way that brings together the necessary critical mass of commodity and enabling services for unleashing the creative potential of the new roles of public displays in urban space and social venues. As future work, we will explore how the WCD fits this new challenge and gather information on the success of the various approaches that we intend to explore.

\section{ACKNOWLEDGEMENTS}

We would like to sincerely thank the Director of the Secondary School Caldas das Taipas, José Augusto Araújo for giving permission to run the case study and the teachers who gently agreed to participate in the interviews. We would like to thank Bruno Silva and Alberto Rego for their contributions regarding software development and field work, respectively.

We would also like to thank the two anonymous reviewers for their comments.

Finally, we would also like to express our gratitude to Gilbert Cockton for his insightful comments and suggestions.

\section{REFERENCES}

Brignull, H., Izadi, S., Fitzpatrick, G., Rogers, Y., \& Rodden, T. (2004). The introduction of a shared interactive surface into a communal space. In Proceedings of the 2004 ACM Conference on Computer Supported Cooperative Work (pp. 4958). Chicago, Illinois, USA: ACM.

Carroll, J. (1995). Scenario-Based Design. Envisioning Work and Technology in System Development. New York: John Wiley and Sons.
Carroll, J. (2000). Five reasons for scenario-based design. Interacting with Computers, 13, 43-60.

Cockton, G. (2004). Value-centred HCI. In Proceedings of the third Nordic Conference on Human-computer Interaction (pp. 149-160). Tampere, Finland: ACM.

Cockton, G. (2005). A development framework for value-centred design. In CHI '05 extended abstracts on Human factors in computing systems (pp. 1292-1295). Portland, OR, USA: ACM.

Cockton, G. (2006). Designing worth is worth designing. In Proceedings of the 4th Nordic conference on Human-computer interaction: changing roles (pp. 165-174). Oslo, Norway: ACM.

Cockton, G. (2008). Designing Worth Connecting Preferred Means to Desired Ends. Interactions, 15(4), 54-57.

Cockton, G. (2009). When and Why Feelings and Impressions Matter in Interaction Design. Presented at the Kansei 2009: Interfejs Użytkownika - Kansei w praktyce, Invited Keynote Address, Warszawa. Retrieved from http://www.cs.tut.fi/ihte/projects/suxes/pdf/Cockto n_Kansei\%202009\%20Keynote.pdf.

Cockton, G., Kujala, S., Nurkka, P., \& Hölttä, T. (2009). Supporting Worth Mapping with Sentence Completion. In Gulliksen, J., Kotzé, P., Oestreicher, L., Palanque, P., Prates, R. O., \& Winckler, M. (Eds.), Proceedings of INTERACT 2009, Part II (LNCS 5727) (pp. 566-581). Springer.

Dantec, C. A. L., Poole, E. S., \& Wyche, S. P. (2009). Values as lived experience: evolving value sensitive design in support of value discovery. In Proceedings of the 27the International Conference on Human Factors in Computing Systems (pp. 1141-1150). Boston, MA, USA: ACM.

Følstad, A., Brandtzæg, P. B., Gulliksen, J., Näkki, P., \& Börjeson, M. (2009). Proceedings of the INTERACT 2009 Workshop: Towards a manifesto of Living Lab co-creation.

Friedman, B. (1996). Value-sensitive design. Interactions, 3(6), 16-23.

Friedman, B., Kahn Jr, P. H., \& Borning, A. (2006). Value Sensitive Design and Information 
Systems. In P. Zhang \& D. Galletta (Eds.), Human-Computer Interaction and Management Information Systems: Foundations, Advances in Management Information Systems (Vol. 6, pp. 348-372). London, England: M.E. Sharpe.

Friedman, B., \& Peter H. Kahn, J. (2003). Human values, ethics, and design. In J. A. Jacko \& A. Sears (Eds.), The human-computer interaction handbook: fundamentals, evolving technologies and emerging applications (pp. 1177-1201). L. Erlbaum Associates Inc.

Huang, E. M., Mynatt, E. D., Russel, D., \& Sue, A. (2006). Secrets to Sucess and Fatal Flaws: The Design of Large-Display Groupware. IEEE Computer Graphics and Applications, 26(1), 3745.

Johnson, D. G. (2004). Computer Ethics. In L. Floridi (Ed.), Philosophy of Computing and Information (pp. 65-75). Blackwell Publishing.

José, R., Otero, N., Izadi, S., \& Harper, R. (2008). Instant Places: Using Bluetooth for Situated
Interaction in Public Displays. IEEE Pervasive Computing, 7(4), 52-57.

Löwgren, J., \& Stolterman, E. (2007). Thoughtful Interaction Design: A Design Perspective on Information Technology. MIT Press.

O'Hara, K., Perry, M., Churchill, E., \& Russell, D. (2003). Public and Situated Displays: Social and Interactional Aspects of Shared Display

Technologies. Kluwer Academic Publishers.

Preece, J., Rogers, Y., \& Sharp, H. (2002). Interaction Design: beyond human-computer interaction. New York: John Wiley \& Sons.

Sellen, A., Rogers, Y., Harper, R., \& Rodden, T. (2009). Reflecting human values in the digital age. Commun. ACM, 52(3), 58-66.

Storz, O., Friday, A., Davies, N., Finney, J., Sas, C., \& Sheridan, J. (2006). Public Ubiquitous Computing Systems: Lessons from the e-Campus Display Deployments. Pervasive Computing, IEEE, 5(3), 40-47

Nuno Otero is a Research Fellow at the University of Minho. His research interests include interaction design and human-robot interaction. The general goal of his investigation is the understanding of how everyday human activities are affected and can be enhanced through the design of interactive technologies. He holds a PhD in Computer Science from the University of Sussex. Contact him at nuno.otero@dsi.uminho.pt

Rui José is an Assistant Professor at University of Minho in Portugal, where he has been active in Ubiquitous Computing research. He is the coordinator of the Research Program on Situated Displays for Smart Places, a multi-disciplinary long-term initiative centred on the concept of situated displays as shared, networked, pro-active artefacts that become an integral part of their environment. He holds a $\mathrm{PhD}$ in Computer Science from Lancaster University. Contact him at rui@dsi.uminho.pt. 